\title{
Feminismo y literatura (argentina) mundial: Selva Almada, Mariana Enríquez y Samanta Schweblin
}

\author{
"El lugar más sombrío está siempre debajo de la lámpara” \\ Proverbio chino
}

\section{Introducción}

La literatura escrita por mujeres argentinas ha adquirido un protagonismo insólito en el siglo XXI: nunca antes habían publicado tantas escritoras ni habían alcanzado tal nivel de legitimidad, en la academia y en el mercado, en el circuito nacional y en el transnacional. Por supuesto, este hecho no sucede in promtu sino que es consecuencia de la articulación de un discurso literario de raigambre feminista que se ha venido gestando desde los años setenta y ochenta (v.g., Sylvia Molloy, Hebe Uhart, Luisa Valenzuela, Angélica Gorodischer, Claudia Piñeiro, Ana María Shua, Diana Bellesi, Tununa Mercado, María Moreno, etc.), y que alcanza su periodo de mayor eclosión y desarrollo en los últimos lustros (v.g., Gabriela Cabezón Cámara, Fernanda García Lao, Mariana Dimópulos, Jimena Néspolo, Gabriela Bejerman, Selva Almada, Romina Paula, Inés Acevedo, Patricia Ratto, Florencia Abbate, Pola Oloixarac, Samanta Schweblin, Ariana Harwicz, Mariana Enríquez, María Gainza, Lola Copacabana, etc.). Pero, ¿qué factores han contribuido a esta efervescencia feminista en la literatura argentina actual?

Por un lado, esta escritura de mujeres se enmarca en la "nueva” (Drucaroff Los prisioneros) o "novísima” novela argentina (Gallego Cuiñas “Comienzos. ..”), que ha tenido gran protagonismo en la escena cultural latinoamericana, mediante el cultivo de temas como el trauma del pasado dictatorial, la memoria falsa, los fantasmas y/o desaparecidos, el cuerpo, la preocupación por el lenguaje, el diálogo con los medios de comunicación, la civilibarbarie, etc. (Drucaroff Los prisioneros). Aunque lo más significativo de la narrativa argentina del siglo XXI, en mi

Nota: Este trabajo se encuadra dentro del proyecto I+D LETRAL “Comienzos de la novísima literatura latinoamericana (2001-2015)" del Ministerio de Economía Competitividad de España (ref. FFI2016-79025- P); y de la Unidad de Excelencia IBERLAB de la Universidad de Granada.

Ana Gallego Cuiñas, Universidad de Granada

Ә Open Access. (C) 2020 Ana Gallego Cuiñas, published by De Gruyter. (cc) BY-NC-ND This work is licensed under a Creative Commons Attribution-NonCommercial-NoDerivatives 4.0 International License.

https://doi.org/10.1515/9783110673678-006 
opinión, no es el tratamiento de estas problemáticas o el uso de ciertas formas literarias, sino justamente la irrupción, masiva y reveladora, de mujeres escritoras y de poéticas feministas. Esta circunstancia no se ha destacado lo suficiente en importantes estudios sobre la materia: Josefina Ludmer en Aquí América Latina (2010) habla de un sistema literario hecho de "escritores jóvenes y mujeres", pero solo menciona a cinco escritoras ${ }^{1}$, que comparten en la nueva centuria "temporalidades globales"2, que están fuera de la nación o en una "no nación" (89) ${ }^{3}$. Por su parte, Elsa Drucaroff en Los prisioneros de la torre (2011) contempla a treinta mujeres en su nómina de setenta y dos escritores pertenecientes a lo que llama “segunda generación postdictadura” (213-215), nacida entre los setenta y principios de los ochenta; toda vez que dedica un tema a la "mirada femenina”, donde realiza una fecunda lectura de género, aunque no aplica una perspectiva netamente feminista ${ }^{4}$. Y, por último, Beatriz Sarlo en Ficciones argentinas. 33 ensayos (2012) atiende solo a cinco mujeres: Mariana Enríquez, Matilde Sánchez, Mariana Dimópulos, Selva Almada y Laura Alcoba ${ }^{5}$. Asimismo en listas como la que configuró la revista Granta en 2010 o la reciente Bogotá39 del Hay Festival en 2017, donde se eligieron a los treinta y nueve mejores escritores en lengua castellana menores de 39 años y tan solo hallamos trece mujeres. No llega ni a la mitad, algo que llama mucho la atención, habida cuenta de la notable -calidad de la- producción actual de mujeres escritoras ${ }^{6}$.

Pareciera entonces que buena parte de los académicos más consagrados no se ha hecho eco suficiente del extraordinario calibre de esta novísima escritura de mujeres, que no ha conseguido el mismo tratamiento y circulación que la de sus pares hombres. Sin embargo, han proliferado sobremanera en la última década

1 Tampoco se detiene en el análisis de ningún texto de mujeres escritoras, a excepción de unas pocas: Matilde Sánchez, Clara Obligado, María Moreno e Inés Fernández Moreno, entre otras.

2 Yo hablaría más bien de "subjetividades globales", donde está implícita la temporalidad.

3 Ludmer incluye en este apartado los ejemplos de Aira, Libertella y Chejfec.

4 Sí encontramos varios apartados en los que transita cuestiones de género: "Nueva mirada masculina y femenina: 'loquitas' y 'locas”' (274-281); “Madres filicidas: el lado oscuro de un orden simbólico negado" (351-364); "Mirada femenina: una breve introducción” (454-476).

5 Tampoco lo hacen libros de ensayos menos académicos que abordan la narrativa argentina actual, como los de los escritores Juan Terranova, que en Los gauchos irónicos (2013) se centra en ocho jóvenes, entre los cuales solo hay una mujer (Pola Oloixarac); y Maximiliano Crespi que en su agudo y controvertido Los infames (2015) únicamente recala en Selva Almada y María Pía López, entre una decena de autores.

6 El hecho solo puede explicarse por la pervivencia de un sustrato ideológico machista que sigue invisibilizando a la mujer, desvalorizándola, y relegándola a un segundo lugar con respecto al hombre/escritor. 
los estudios de caso aplicados a escritoras y textos en el ámbito de la crítica argentina, por parte de los investigadores más jóvenes, muchos de ellos mujeres. La perspectiva feminista se aplica cada vez más al análisis de la literatura actual, al socaire de las políticas institucionales que promueven la igualdad de género y el feminismo como área de conocimiento propia. A esto hay que sumar que las mujeres han ido ocupando nuevos espacios públicos de legitimidad en la Argentina; un factor social que ha contribuido a ensanchar su presencia también en el discurso literario:

la política argentina posterior al retorno de la institucionalidad democrática, desde 1983, está atravesada por la presencia de las mujeres: la lucha por los derechos humanos de las Madres y Abuelas de Plaza de Mayo, el asesinato en 1997 -aún impune- de la trabajadora Teresa Rodríguez en las primeras manifestaciones sociales en Cutral-có (Neuquén), que la transforman en un símbolo del movimiento piquetero, y la visibilidad de los cuerpos configurados por el género, desde 2015, a partir de las convocatorias " $\mathrm{Ni}$ Una Menos"7. (Angilletta 96)

De otro lado, si hacemos una lectura materialista del objeto literatura feminista argentina es fácil comprobar que el crecimiento de su visibilidad en el campo literario también viene acompañado del auge de las editoriales independientes, que, aunque tienen un radio de acción local/nacional, funcionan como gatekeepers de la literatura (argentina) mundial. La expansión de la industria editorial, es decir, las mejoras de las condiciones materiales del sector, ha favorecido, a todas luces, a las escritoras. Para muchos de estos sellos la apuesta por sectores de mercado tan valorados en la actualidad como el de las mujeres y el de los autores emergentes es fundamental para la configuración de sus catálogos. Sin embargo, cuando ponemos el foco en una escala mayor, en las llamadas literaturas mundiales, la escritura de mujeres sigue invisibilizada. De tal manera que, si las mujeres ocupan un lugar menor en la circulación trasnacional de la literatura latinoamericana, su condición es doblemente subalterna en el espacio de la literatura mundial: por ser latinoamericanas y por ser mujeres. La explicación puede encontrarse en el hecho de que las escritoras más ensalzadas y consagradas en el sistema global han sido, hasta fines de siglo XX, aquellas en que no se vislumbra tanto la diferencia genérica, es decir: su literatura está más asimilada a la canónica, de corte patriarcal ${ }^{8}$.

7 Hay que mencionar también el gobierno de la presidenta de la República Argentina Cristina Kitchner, entre 2007 y 2015, periodo en que se aprobó el matrimonio igualitario (2010) y la identidad de género (2012). Sin embargo, no ha conseguido aprobarse la ley del aborto: el senado argentino volvió a mostrar su negativa en agosto de 2018. El cuerpo de la mujer sigue estando "en disputa".

8 Hagamos un repaso a los temas que han hecho destacar a las últimas mujeres que han ganado el Premio Nobel de Literatura: Svetlana Alexiévich (conflicto bélico); Herta Müller 
$\mathrm{O}$ aquellas en que la diferencia genérica es un producto en sí mismo, ora por el relato de asuntos femeninos ora por su lucha abiertamente feminista ${ }^{9}$, traducida en la narración de situaciones de abuso, violencia y opresión.

A la vista de lo expuesto, he seleccionado una nómina de tres escritoras mujeres nacidas en la Argentina en las década de los setenta (Selva Almada, Mariana Enríquez y Samanta Schweblin), y un corpus de tres novelas que pueden ser leídas como feministas: Distancia de rescate (2014), Chicas muertas (2014) y Éste es el mar (2017). Las tres obras han sido editadas por un gran grupo editorial, Literatura Random House, que desde 2015 acoge en su catálogo a cada vez más jóvenes latinoamericanas, labor mercadotécnica -lo joven es una cuota de mercado muy bien definida- orientada a poner en circulación el fetiche de lo nuevo ${ }^{10}$, que incita a la deseabilidad y al consumo neoliberal, como ya hicieran Planeta y Alfaguara en los noventa. No obstante, en el siglo XXI los grandes sellos actúan con menor margen de riesgo y la mayoría de las veces editan a novelistas emergentes cuando atesoran cierto reconocimiento previo (periodistas, dramaturgos, músicos, cuentistas o poetas). Sucedió con Selva Almada, que después de publicar varias obras en editoriales independientes (v.g., Mardulce que sacó a la luz El viento que arrasa en 2012) y conseguir el beneplácito de una de las gatekeepers más relevantes de la crítica argentina, Beatriz Sarlo, publicó Ladrilleros en 2013 en Lumen (Random House, España) ${ }^{11}$ con la que fue finalista del Premio Tigre Juan. En 2014 la crónica Chicas muertas apareció en Literatura Random House directamente y ahí comenzó su mundialización: fue finalista del Premio Rodolfo Walsh, traducida al francés, al portugués y al turco; y se vendieron sus derechos a la televisión. En 2017 se tradujo El viento que arrasa al inglés, y, desde entonces, su circulación es mayor, aunque su proyección internacional es menos prominente que la de Enríquez y Schweblin, como comprobaremos a continuación.

Mariana Enríquez, la más precoz de esta tríada, comienza publicando su primera novela, Bajar es lo peor (1995), en una gran editorial, Espasa-Calpe ${ }^{12}$, Luego saca en Emecé Cómo desaparecer completamente (2004) y Los peligros de fumar en la cama (2009). Pero será en 2016 cuando Anagrama apueste por Las

(totalitarismos); Doris Lessing (conflictos raciales); Wislawa Szymborska (memoria); Nadine Gordimer (economía y corrupción). Desde la década de los noventa hasta hoy, solo encontramos a tres escritoras feministas: Toni Morrison, Elfriede Jelinek y Alice Munro.

9 Basta pensar en el bestseller de Margaret Atwood, El cuento de la criada.

10 Se trata, además, de la primera novela de Samanta Schweblin y de la primera crónica de Selva Almada.

11 En la Argentina salió en Mardulce Editora.

12 El hecho es insólito, pero también se trataba de la década de los noventa, donde el panorama editorial estaba en plena efervescencia y los catálogos de las grandes editoriales aún publicaban a bastantes autores jóvenes y noveles. 
cosas que perdimos en el fuego y Enríquez comience su andadura mundial: el mismo libro de cuentos será publicado por Vintage Español (Random House), y traducido al inglés por Megan McDowell al año siguiente ${ }^{13}$, Fue incluido en The New Yorker y nombrado libro del año por Boston Globe, PASTE Magazine, Words Without Borders, Grub Street, Remezcla y Entropy Magazine. También en 2017 Literatura Random House sacará a la luz Éste es el mar en Buenos Aires, y en 2018 en España. Otro dato interesante que no hay que soslayar en esta breve semblanza de la trayectoria en el mercado (editoriales, traducciones, premios) de nuestras escritoras es que tanto Selva Almada como Mariana Enríquez, con Chicas muertas y Éste es el mar han entrado a formar parte de la iniciativa Mapa de las lenguas, que lanzaron Alfaguara y Literatura Random House en 2015 para fomentar la circulación transnacional de determinadas obras de sus catálogos $^{14}$. Ambas obras fueron publicadas en España: la primera en 2015 y la segunda en 2018, operación de selección, producción, circulación y recepción que de alguna manera (pre)supone la (pre)figuración de un futuro canon "latinoamericano" 15 .

Por último, queda por abordar a la más mundializada de nuestras escritoras argentinas y latinoamericanas: Samanta Schweblin, que ganó en 2001 el Premio Nacional de las Artes en Argentina con su libro de relatos El núcleo del disturbio, que fue editado por Destino. En 2008 se hizo con el Premio Casa de las Américas por Pájaros en la boca, que salió en Lumen un año después; y en 2010 fue escogida por la revista Granta como una de las mejores voces de la literatura en lengua castellana. A partir de ahí, consigue el premio Juan Rulfo

13 Sin dudarlo, también influye el hecho de pertenecer a la nómina latinoamericana que representa la agencia catalana Casanovas \& Lynch, en la que también encontramos a reconocidos autores como Rodrigo Fresán, Juan Gabriel Vásquez, Fernando Vallejo, Carlos Franz, etc. Llama la atención el elevado número de latinoamericanos jóvenes -nacidos a partir de la década del setenta- que son representados por esta agencia, entre los que destacan los argentinos: María Gainza, Roque Larraquy y Pola Oloixarac. Véase: http://www.casanovaslynch.com/ authors.html.

14 La iniciativa consistió al principio en publicar en España dos obras de escritores latinoamericanos cada mes -que elige cada filial de América Latina, una de Alfaguara y una de Random House- con una tirada de 500 ejemplares. Al año siguiente, en 2016, comenzó la labor de promoción inversa: de escritores españoles en cada filial latinoamericana, y entre filiales latinoamericanas (v.g., escritores mexicanos, chilenos, etc., que se dan a conocer en Argentina, y viceversa). Véase: https://www.megustaleer.com.ar/noticias/mapa-de-las-lenguas/430\&pre view=S.

15 La circulación transnacional -de facto- en Alfaguara o Literatura Random House se produce en contadas ocasiones (entre ellas, el Premio Internacional Alfaguara de Novela inaugurado en 1998, porque tampoco funcionó “Alfaguara Global”), en que el rédito económico es incontestable. 
en 2012 y en 2014 Literatura Random House la ficha -cuando su capital simbólico está asentado y es sólido- para publicar su primera novela: Distancia de rescate, que la hace ingresar directamente en la literatura mundial. Es traducida al inglés por Megan McDowell ${ }^{16}$, seleccionada por Man Booker International Prize en 2017, y merecedora de los premios Tournament of books al mejor libro publicado en USA y Nouvelle Shirley Jackson Award ${ }^{17}$. Ha sido reseñada en The New Yorker, Vanity Fair, The Guardian y Washington Post, entre otros. Hay que subrayar que no se ha incorporado al catálogo de Mapa de las lenguas porque directamente el grupo editorial decidió publicar Distancia de rescate, y el resto de novelas posteriores, en España. Schweblin no ha necesitado de ese filtro para potenciar su circulación transnacional porque su figura, simbólica y económica, es la de mayor trascendencia internacional, entre las escritoras latinoamericanas de su generación.

En definitiva, las tres autoras de nuestro estudio han publicado en el conglomerado editorial más potente en lengua castellana, Bertelsmann, dentro de Literatura Random House, que se consolida como el sello de los emergentes en vías de consagración. Han sido traducidas a varios idiomas, entre ellos el inglés, y cuentan con potentes agentes literarios y premios (españoles e ingleses) que las avalan. Incluso las tres pueden definirse como escritoras profesionales no solo porque vivan de este trabajo -o de desempeños afines- sino porque se han formado en célebres talleres literarios en Buenos Aires ${ }^{18}$ : Almada en el de Alberto Laiseca, Enríquez en el de Tomás Eloy Martínez y Schweblin en el de Liliana Heker; eventualidad no baladí para entender la manera en que se ha profesionalizado el oficio de escritor en el siglo XXI, cuya aura romántica se ha terminado de diluir casi por completo, si es que quedaba algo (véase Riveiro). Además, otro factor que las une es la naturaleza de sus propuestas estéticas, que contemplan un manejo subversivo -feminista- del lenguaje, de temas y problemas -globales- que apuntan a la deconstrucción de categorías genéricas binarias y de ciertos imaginarios heteronormativos diseminados por la ideología patriarcal en relación con las ideas de maternidad, la sexualidad, el amor romántico y la violencia machista. En efecto,

16 Podríamos decir que esta traductora es la Gregory Rabassa del siglo XXI, toda una gatekeeper de la literatura latinoamericana mundial en la actualidad: ha traducido a Zambra, Enríquez, Meruane, Zúñiga, Fonseca, etc.

17 Además de que forma parte de la nómina de una de las agencias literarias más potentes del mundo hispano: Carmen Barcells, lo que sin duda ha contribuido a la mundialización de su literatura.

18 Otra hipótesis de trabajo sería considerar los talleres literarios no solo como síntoma de la profesionalización extrema de la escritura como oficio y de la taylorización -y estandarizació $\mathrm{n}$ - de poéticas en la actualidad, sino como un gatekeeper de la literatura latinoamericana mundial. 
en el campo cultural argentino que impulsó en 2015 el movimiento feminista de alcance mundial Ni una menos, se están produciendo en la última década nuevas formas de empoderamiento literarias que merecen un espacio propio para la reflexión crítica, como se podrá comprobar en el análisis que llevaré a cabo en las siguientes páginas.

\section{Una lectura materialista: la literatura (argentina) mundial}

Agentes y editoriales (v.g., Carmen Balcells, CBQ, Random House y Anagrama en las autoras que nos ocupan) son engranajes cardinales de la maquinaria que activa el mercado literario, determinantes en los modos de circulación y recepción de una obra. La dinámica globalizadora que pusieron en marcha los grandes grupos en los noventa supuso una tendencia al centralismo, la polarización y la homogeneización de productos, que quedaron en manos de oligopolios como Planeta y Bertelsmann -propietarios de Penguin Random House- para la literatura en lengua castellana. Estos conglomerados son los que ponen en la órbita mundial a la literatura latinoamericana actual, cuya marca de identidad más reconocida es la lengua castellana. En rigor, el sistema literario en los últimos años se ha expandido, como el mercado, ferozmente fuera de las fronteras nacionales, hasta el punto que ciertas narrativas se han desterritorializado amén de la globalización capitalista y tecnológica, la mundialización de la cultura, la movilidad, la digitalización, el imperialismo de ciertas lenguas y los flujos de intercambio transnacionales. Pero el marbete literatura mundial no se aviene a la autonomía que predicaban Bourdieu y Casanova, sino a una categoría neutralizadora que asimila el objeto literario a un modelo de consumo dominante -anglosajón- basado en la categoría de autor (que funcionan como marcas) - no en la de obra o en estéticas-, que es lo que permite que se lean novelas concretas como mundiales/del mundo. Así, la circulación global se ha impuesto como forma hegemónica de consagración: los libros con más valor simbólico y económico son lo más visibles, los que más se traducen. Entonces, sobreviene otra vez la misma pregunta (a la que los críticos no paramos de darle vueltas, como ratones en una rueda giratoria): ¿qué es la "literatura mundial”? ¿Un modo de producción (tipo de escritura), un tipo de circulación de texto (trasnacional) o una forma de recepción (marco de lectura)?

Las últimas teorías que han dirimido esta problemática responden y ponen el acento en la circulación global de libros, como argumenta Pheng Cheah en What is a World? (5). Para el reconocido crítico de Berkeley, el hecho de que la 
categoría “mundial” se asocie a la circulación transnacional de bienes y al mercado global es un error, porque sería considerar que la globalización tiene un sesgo imperialista, occidental y anglocéntrico ${ }^{19}$. Sin embargo, desde una perspectiva materialista, la lectura neocolonial -la superproducción de objetos y la estandarización de culturas- es innegable; aunque, como defiende Cheah, también haya que atender a las estéticas mundiales, no solo a los aspectos económicos, sociológicos y políticos que implica la globalización ${ }^{20}$. Mi postura crítica en este ensayo abarca sendos aspectos, el económico y el estético, político, ya que las novelas escogidas albergan principios literarios mundiales como “el presente, la experimentación, lo relativo, lo fluido” (Bourriaud 15), y sus tres autoras tienen una proyección global y una circulación internacional.

Siguiendo este eje de pensamiento, habría que tener en consideración que la globalización de la economía ha cambiado la cadena de producción del libro en virtud de dos procedimientos concretos: la racionalización y la concentración de editoriales. A esto se suman otras variables que determinan la circulación del libro: “aires linguistiques, territoires géographiques de distribution, frontiéres nationales qui circonscrivent des espaces juridiques et des politiques publiques, territoires imaginaires qui asoscient des identiés à des lieux et dessinen un horizon d'attente" (Sapiro 7). Para la socióloga francesa, la "mundialización" o "globalización" se manifiesta en el espacio editorial cuando cae el muro de Berlín, los regímenes dictatoriales de España y América Latina, y se intensifica la circulación internacional de libros (7). Aunque este hecho no sea algo novedoso, sí lo es la aceleración y el cambio en los modos de producción, ahora en manos occidentales, debido a las fusiones de los grandes grupos (e.g., Bertelsmann, Rizzoli o Planeta), que han encastrado progresivamente a los mercados nacionales en América Latina (Sapiro 9-10) ${ }^{21}$.

19 Para Cheah la literatura mundial debería explorar cómo determinados textos literarios contribuyen a la comprensión del mundo, a su cambio -a la "mundialización del mundo"- desde una perspectiva normativa, temporal y no espacial.

20 Véanse las últimas monografías coordinadas por Gesine Müller sobre la literatura latinoamericana mundial, el libro reciente de Ignacio M. Sánchez Prado y el de Jorge J. Locane.

21 No obstante, y sorprendentemente, Gisèle Sapiro insiste -con Bourdieu- en que el mercado de bienes culturales tiene una jerarquización y economía propias, autónomas. Para Jorge J. Locane, la autonomía es inviable porque la literatura (latinoamericana) mundial depende fuertemente de proveedores de capital, aunque no ocurriría lo mismo a una escala localizada (véase Locane). Coincido con este argumento aunque considero que la heteronomía permea también los circuitos locales del libro: siempre que haya publicación -siempre que haya un interlocutor, diría Libertella-, siempre que haya producción, y por tanto circulación, por pequeña que sea, hay un mercado de capitales e intereses (creados). 
En segundo lugar, la globalización del mercado editorial no es un proceso uniforme, sino diverso y contradictorio. Por un lado, se han concentrado los modos de gestión de la producción y la distribución en las regiones centrales (Nueva York, Londres, Frankfurt, París, Barcelona, Madrid) ${ }^{22}$, pero a la vez ha aumentado la producción de libros (más escritores y títulos) y ha disminuido la oferta (menos tirada), lo que trae como consecuencia el conocido fenómeno de los libros que nacen muertos. Esto perjudica a los autores noveles, y a géneros menores como el teatro y la poesía; aunque beneficia al más comercial, la novela, que se aviene a la política del best seller y a la rentabilidad a corto plazo (Sapiro 12-13).

Las nuevas reglas del mercado global -que sustituye a la categoría de campo nacional (véase Gallego Cuiñas "Poéticas...")- conllevan la producción y circulación de las literaturas mundiales, o lo que Tim Parks denomina "New Global Novel” en Where I'm Reading. The Changing World of Books (2014), que ha afectado al oficio literario, en cuanto a la percepción que tienen los autores de quién es su audiencia: "There is a growing sense that for an author to be considered 'great' he or she must be an international rather than a national phenomenon" (Parks s.p.). Y eso implica orientar su producto al mundo anglosajón, motor del mercado internacional, que pondera la legibilidad, lo fácilmente traducible, lo que circula y no se resiste. El sentido estético es abandonado en pos del comercial -la calidad literaria se mide desde hace tiempo por la circulación transnacional de un autor- y la especificidad es desdeñada en beneficio del objeto estandarizado, que propicia un mayor número de traducciones y de ventas.

En lo que respecta al lugar que ocupa el dispositivo literatura latinoamericana en el sistema mundial del siglo XXI, hay que tener en cuenta dos variables: que la novela en lengua castellana tiene una condición menor (se traduce y circula menos) que la de lenguas hegemónicas como el inglés, el francés y el alemán; y que la industria editorial latinoamericana sigue dependiendo de la supremacía -económica- que ha ejercido España, desde los años ochenta, sobre este sector. Hasta el punto que, en la mayoría de ocasiones, un escritor de América Latina ha de ser publicado por un gran grupo editorial en España para ser traducido y entrar en el circuito internacional, que sigue ejerciendo así de gatekeeper de la literatura latinoamericana mundial.

Por último habría que precisar que una vez fabricado ese producto, el de la literatura latinoamericana mundial, es recibido, leído, desde la lógica hegemónica de la tradición occidental. Y en esta predomina una bolsa de valores eurocéntricos, universalizantes y totalitarios que privilegian la alta literatura y la

22 Aunque la industria dominante es la anglosajona. 
forma novelística, el género dominante, el que nace con el capitalismo, el más legible y consumible. Teniendo en cuenta estos factores, las obras de nuestro corpus encajan a la perfección en el cerco mundial: se trata de novelas (y una crónica), abordan temas globales (el feminismo, la ecología y el mercado de la música) y sus autoras son jóvenes y argentinas, otros dos valores que cotizan a la alza. ¿Por qué? El campo nacional argentino -que no deja de ser un "artefacto cultural" (Blanco et al. 13) al que dicen pertenecer las autoras- es el que goza de un alcance superior, simbólico y económico, dentro del circuito mundial de las letras latinoamericanas. Basta pensar en la feria internacional del libro de Frankfurt que tuvo a Argentina como país invitado en 2010, y que originó el Programa Sur para favorecer la traducción de obras argentinas a otras lenguas; hecho que ha contribuido a la mundialización de esta literatura sobre otras de Latinoamérica. También el salón internacional del libro de París se dedicó a Buenos Aires en 2011, y a la Argentina como país de honor en 2014: ambos acontecimientos impulsaron la circulación europea de sus escritores, sobre todo de los emergentes. "Sin pasar por alto que su presencia es profusa en listas como las de Granta o Bogotá39. Con lo anterior queda claro que existen nacionalidades latinoamericanas, como la argentina, que se han fetichizado en el mercado global, habida cuenta de su nutrido capital simbólico y desarrollo económico” (Gallego Cuiñas, “Las narrativas...” 11).

\section{Lecturas feministas de las narrativas argentinas del siglo XXI}

Como es sabido, las teorías feministas tuvieron especial calado en el campo literario latinoamericano a partir de la década de los ochenta, cuando se deconstruyen los modelos de la cultura heteropatriarcal y la mujer se vuelve agente de cambio en virtud de un feminismo de la diferencia (Cixous, Irigaray o Kristeva). Justo en ese momento estalla el llamado Boom de la narrativa escrita por mujeres $^{23}$, que catapulta internacionalmente a una serie de escritoras que orientan sus publicaciones a una lectora femenina a través de temas como: el (des)amor romántico, la cocina, y el erotismo. En realidad, las autoras que se mundializaron más (v.g., Isabel Allende, Laura Esquivel, Ángeles

23 El solo hecho de que exista esta categoría en el mercado "narrativa de/para mujeres" (frente al escritura producida por hombres que no se define sino por su universalidad) es un síntoma de su subalternidad en el sistema literario. 
Mastretta) de algún modo reproducían en sus poéticas “sentimentales” roles de la ideología patriarcal, aunque su objetivo fuera dar visibilidad a una voz propia de las mujeres -el célebre "hablar en femenino"-, que había quedado orillada por el discurso literario masculino. Sin embargo, sus poéticas no terminan de discutir el esencialismo de la categoría de género y siguen vinculando, aunque sea desde una mirada propia, el espacio doméstico de la casa y la labor reproductiva con la mujer, con lo femenino, y con la familia.

En cambio, otras autoras del mismo periodo, Rosario Castellanos y Elena Poniatowska, decidieron apropiarse de los grandes temas de la escritura masculina -la Historia, la Política, la Filosofía- con el fin de armar un discurso otro capaz de subvertir la versión oficial de la Historia e incorporar a los oprimidos y excluidos del centro de poder, generando relatos contrahegemónicos que ponían sobre las cuerdas la ideología patriarcal: no solo en el plano temático sino también formal ${ }^{24}$. A esta línea se adscribieron después las argentinas Hebe Uhart, Luisa Valenzuela y Angélica Gorodischer que fueron más allá: deslegitimaron en sus poéticas al "Sujeto Fundador" -Foucault dixit- de los grandes relatos de la nación argentina, y vindicaron socialmente a la mujer marginada para elaborar una imagen pluridentitaria, que escapa a los roles sexuales impuestos por la heteronormatividad. Y lo hicieron desde un discurso, y una estética, diferente.

Ya a partir de fines del siglo XX, y hasta hoy día, el feminismo ha ido abriéndose a otros enfoques como la teoría queer ${ }^{25}$ (Butler y la performatividad del género y la identidad), el postfeminismo (Haraway), los nuevos materialismos (el posthumanismo y el "thing power" de Jane Bennett o el feminismo materialista de Elizabeth Gross), la pospornografía (que predica Paul B. Preciado) o el feminismo latinoamericano de Marcela Lagarde, focalizado en la violencia y en los procesos de subjetivación -subalternos- de las mujeres latinoamericanas (véase MedeirosLichem). En cuanto a Argentina, además de la reconocida filósofa María Luisa Femenías, que defendía un lugar alternativo para el feminismo latinoamericano, tenemos a la socióloga Karina Bidaseca que aboga por un "feminismo decolonial" que visibiliza a las "otras" del "feminismo hegemónico" (Audran 93), aunque ninguno de estos últimos ha tenido gran calado en el discurso literario argentino.

En este horizonte de feminismos, se ha ido desarrollando una narrativa argentina que hace "trizas el viejo cliché sobre lo que debería ser la escritura de

24 Nótese que estas escritoras son de las más consagradas por la crítica mundial, habida cuenta del tratamiento en sus narrativas de temas "masculinos", aunque la mirada sea "feminista".

25 Véase a este respecto el volumen editado por Falconí en 2016: Resentir lo queer en América Latina: diálogos desde/con el Sur. 
mujeres” (Drucaroff, Los prisioneros 462). ¿De qué modo? Se pueden distinguir al menos dos mecanismos claros: primero, la reapropiación de recursos como el humor negro y la violencia, que eran ínsitos a la escritura masculina y al papel social del hombre. Segundo, la deconstrucción y reconstrucción de los procesos de subjetivación femenina. Ya no se trata de narrar lo que dicen las mujeres, sino lo que no dicen. El objetivo no es solo tener acceso a la palabra sino descorrer el velo ideológico que el discurso hegemónico patriarcal ha extendido sobre el cuerpo de la mujer y sus funciones: como madre, como amante, como víctima de la violencia. Así, esta novísima narrativa feminista muestra, en un acto político, los límites, los agujeros, las sombras (Ludmer, Clases 98) de la feminidad, aunque sin adoptar una postura decolonial para la subjetividad - subalterna- argentina. El punto de partida de las propuestas narrativas de las argentinas Almada, Enríquez y Schweblin es un feminismo hegemónico, que desafía tanto la ideología patriarcal como la literatura femenina, poniendo en jaque la institución del matrimonio, los roles de esposa y madre, la familia y la misma identidad -en devenir y performática- de la mujer mundial (no específicamente latinoamericana). ¿Cómo lo logran? Representando zonas de debate "mundiales", muy productivas desde los enfoques feministas actuales, que son deconstruidas y resignificadas: la maternidad, el amor romántico, y la violencia machista; los topoi de la escritura de mujeres que más y mejor- circulan en la literatura mundial. Sin duda, la resistencia feminista es hoy un mercado en expansión, valga el oxímoron. La literatura mundial, constituida en/por/para el mercado global, pone a circular textualidades disidentes - ma non troppo- cuando hay una oferta y una demanda crecientes. Y la narrativa argentina escrita por mujeres en el siglo XXI se ha convertido en uno de los centros mundiales ${ }^{26}$ de producción literaria feminista (desde el costado hegemónico), cuya naturaleza desentrañaremos a continuación sobre la base de sus principales problemáticas ${ }^{27}$.

26 El policentrismo y la multiterritorialidad son consustanciales a la producción de literatura mundial.

27 Hay detalles no baladíes en las portadas de estas tres obras que hacen alusión inequívoca a la naturaleza, que se ha vinculado con la mujer. En Schweblin hay un pájaro (que está sobre granadas, imagen masculina); en Enríquez, un rielo de luna sobre un mar de plumas (en alusión "femenina" a la magia de las hadas); y en Almada, un río de lodo entre arbustos (una imagen "femenina" en descomposición, como los cuerpos de las chicas muertas). El análisis paratextual de estas publicaciones excede el espacio de este artículo, pero merecería una exégesis más desarrollada. 


\subsection{La maternidad}

Desde el ecuador de la segunda mitad del siglo XX, la escritura feminista argentina bascula entre el afán de construir subjetividades públicas fuera de lo maternal o plantear la maternidad desde la compleja relación con el hijo/hija. Nora Domínguez en De dónde vienen los niños. Maternidad y escritura en la cultura argentina (2007) hace un nutrido recorrido por las diferentes representaciones literarias de la maternidad en la Argentina del siglo XX y concluye que la madre ha sido fagocitada por el hijo en el discurso literario, sin lograr subvertir esa relación de dominación (Maradei 3). Sin embargo, en el siglo XXI las escritoras argentinas atienden a aspectos de la maternidad que han estado excluidos tanto del marco de lo social como del marco literario: el parto, la lactancia, la menstruación, las relaciones sexuales de la mujer/madre, etc. (Rowinsky 429). Incluso han puesto a circular un relato de la maternidad "resistida, denegada o impuesta" (Maradei 3-4) que desestabiliza la normatividad "procreativa" como significante político conservador, ya que promueve la institución familiar y la propiedad privada: “Al emitir este discurso regenerador con respecto a la mujer por medio de la literatura, se logran crear nuevos parámetros de acción y reacción ante las premisas de lo que 'debe ser/ser' la mujer, para volcarlo a un campo mucho más amplio, el de 'querer ser/ser”' (Rowinsky 428).

En rigor, desde la etapa Postfordista o la Nueva Economía que supuso la incorporación masiva de mujeres al trabajo -sobre todo a partir de la década de los ochenta/noventa- el discurso literario de la maternidad se abre a nuevos planteamientos -políticos- disímiles: desde la negativa a la procreación (v.g., Lina Meruane); a la figura de la mala madre (v.g., Dimópulos o Harwicz); o la defensa del aborto ${ }^{28}$ (v.g., Shua o Piñeiro) ${ }^{29}$. Como diría Cixous, el significante unívoco mujer/madre se auto(de)construye en la segunda década del siglo XXI con una narrativa propia que revela más sombras que luces, en el intento de dinamitar el mito y estereotipo - patriarcal- de la experiencia maternal, teñida antaño de un idealismo casi místico. Una de las pioneras en este rubro deconstructor, en el campo literario argentino, es Ana María Shua. En su cuento “Como una buena

28 Este continúa siendo uno de los grandes tabúes en la literatura y sociedad argentinas (e hispánicas en general).

29 Dentro del feminismo hay distintas posiciones: las que abogan por una maternidad/paternidad igualitaria, y las que defienden el reconocimiento de la "diferencia": solo una madre puede embarazarse, parir, amamantar. En este sector, hay incluso una línea más extremista que defiende lo que podríamos llamar una "maternidad ecológica”: partos no intervenidos quirúrgicamente, lactancia a tiempo completo, pañales libres de plástico, no vacunación de hijos/as, etc. 
madre", "trabaja la maternidad desde las pulsiones monstruosas y el humor negro” (Drucaroff, Los prisioneros 364). A partir de ese momento, no ha hecho sino aumentar el número de mujeres escritoras que exponen el lado sombrío de la maternidad desde un punto de vista feminista, subversivo. Los cuentos de Mariana Enríquez, Alejandra Laurencich, Gabriela Bejerman; la poesía de Fernanda Laguna y Marina Yuszczuk; o las novelas de Inés Acevedo, Ariana Harwicz, Mariana Dimópulos y Samanta Schweblin plantan cara al ideario dulce y gratificante de la experiencia maternal desde el tabú del filicidio, mostrando sin ambages la parte negativa de esta imposición social: la asfixia de la dependencia madre-hija, la colisión con la subjetividad, la resemantización del sexo y de las relaciones de pareja.

Y la novela que mejor ilustra esta zona temática es Distancia de rescate. El relato se compone de dos voces - la de David y Amanda- que arman un diálogo trufado de imágenes ${ }^{30}$, fragmentos, silencios y ambigüedades, abierto a interpretaciones que se instalan en el suspense narrativo y la "reflexión metaficcional” (De Leone 66). Amanda es una madre que se marcha sola con su hija Nina de vacaciones al campo y que expone desde el comienzo su relación maternofilial en términos conflictivos: la dependencia, el miedo, la preocupación, la falta de libertad ${ }^{31}$ y la problemática de la identidad. En un contexto rural donde se cultiva soja contaminada -el campo ha pasado de ser sueño a pesadilla ${ }^{32}$ por la explotación del capitalismo global- la lectura ecológica se trenza con la fantasía y lo siniestro, cuando se aborda el tema de la transmigración de almas en los hijos. Le sucede a David, que bebe agua contaminada por un descuido materno (una mala madre), y se transforma en un niño-monstruo, un niño otro que tiene otra alma, pero el mismo cuerpo (gracias a una curandera) ${ }^{33}$; un hijo que su madre rechaza en una pulsión filicida (Drucaroff, "La cicatriz. ..” 4): “Te llamó 'monstruo', y me quedé pensando también en eso. Debe ser muy triste ser lo que sea que sos ahora, y que además tu madre te llame "monstruo"” (Schweblin 35). Luego Nina, la hija de Amanda, también se contamina, y la culpa vuelve a recaer en la figura materna: “¿Se trata entonces de otra cosa? ¿Es porque hice algo mal? ¿Fui una mala madre?” (116). Nos encontramos con

30 La crítica ha resaltado la huella de David Lynch en su poética (De Leone 72).

31 El hilo invisible que mida la "distancia de rescate" también es una atadura que impide la libertad de movimiento de la madre. Y lo peor, es que -como refiere la novela- es algo que se hereda, forma parte de la tradición.

32 Drucaroff habla de civilibarbarie por la fusión de campo y contaminación ("La cicatriz...” 3). 33 No hay un hospital cercano, y la madre tiene que recurrir a la santería, seudociencia común en el campo argentino. 
un grupo de niños-monstruos (véase González Dinamarca) que tienen el cuerpo mutilado, deforme por la contaminación de los campos y el desarrollo de los transgénicos: marginados en el margen (rural) por la política neoliberal sus cuerpos se transforman. Son sus almas pero no son sus cuerpos. Son a medias, como David. Es decir: no son. O son otros.

Pero la verdadera tragedia reside en que Amanda no puede hacer nada para impedirlo: falla como madre, en su rol normativo, y se convierte en mala madre. La identidad pues se separa de lo material y se entiende como disidente, del mismo modo que la sexualidad, que se cristaliza en la tensión erótica entre Carla -la vecina- y Amanda. Así, Samanta Schweblin desactiva el dispositivo de identidad genérica que contienen los cuerpos: su hija Nina pasa a habitar el cuerpo de David, el hijo de Carla; el objeto de deseo de Amanda. Como indica Drucaroff: en "Distancia de rescate el deseo de la madre es deseo de persona y eso se pone en juego: Amanda ama a su hija pero también desea -casi imperceptiblemente- a otra mujer. Su mirada/voz narra a Carla con un erotismo intenso, velado y sutil" ("La cicatriz. .." 5). La escritora argentina reemplaza la noción de sujeto por la de agente social, de ahí que la identidad subjetiva de la narradora sea performática, como la de los hijos. Sin embargo, Amanda es castigada cuando desea a otra persona, porque al final su hija muere justo cuando la madre imagina/desea una vida con Carla. El deseo en la madre es reprimido y negado por el orden patriarcal heteronormativo, máxime cuando se trata del mismo sexo, de los mismos cuerpos. La imagen de la mujer se delinea en el texto como fuera de la norma, aunque ambas mujeres intenten cumplir con sus papeles de esposas y madres, en los que terminan fracasando. De hecho, la figura masculina en la novela está prácticamente ausente, encarnada en los maridos de Carla y Amanda. El primero es comparado con un animal y el segundo, cuando llega después de la muerte de su mujer, no se da cuenta de "lo importante": no ve ninguna transformación ni en el alma de David -que es la de Nina- ni ve la plaga oculta de los campos (Schlickers 14).

Al final Distancia de rescate demuestra que el género es una forma más de ideología, ya que Samanta Schweblin presenta un cuerpo y una escritura que se unen configurando una materia que se transforma, fuera de la norma, un lugar intermedio, ambiguo y plural, como la identidad genérica. Se impone pues una lectura del texto desde el feminismo queer, desplazado al lugar de enunciación de Donna Haraway y a su idea de lo monstruoso. Como hace notar Audran, en el siglo XXI hay una proliferación de cuerpos-monstruos en la literatura argentina que se conciben como "espacio de resistencia y de supervivencia, se hace lugar de enunciación y de transformación performativo” (81). Estos personajes mutantes -como madre/hija- cristalizan una posición crítica, tanto feminista (en contra de la idea de rescate maternal) como ecologista (en contra 
de los transgénico), que circula muy bien por la agenda de la literatura mundial (en su costado más alternativo).

\subsection{El amor romántico}

Ya he hecho alusión en el epígrafe anterior a la actitud subversiva en el tratamiento del amor romántico que lleva a cabo Samanta Schweblin. Pero será Mariana Enríquez la que profundice más en las raíces patriarcales del amor en Éste es el mar, novela en la que confronta estereotipos femeninos como el amor platónico, la mitomanía, la idea de comunidad femenina, y la crueldad para activar un dispositivo de empoderamiento que pasa por la disolución de códigos binarios: amor carnal/amor ideal; eros/tanatos; cultura de masas/educación sentimental, etc.

El argumento de esta novela fantástica es sencillo: las "Luminosas" son seres sobrenaturales, un "Enjambre" de mujeres adolescentes que actúan como fans, musas y asesinas monstruosas, que confabulan entre sí para hacer que famosos músicos rockeros como Kurt Kobain, John Lennon o Jim Morrison se conviertan en dioses de leyenda a través de una muerte repentina y trágica. La Luminosa Helena es la protagonista y con ella vemos el lado sombrío del fanatismo, la titánica fuerza de una comunidad de mujeres jóvenes, alocadas y empoderadas, hiperconscientes de que sin ellas no existirían los mitos del rock. De nuevo, en esta obra de Enríquez los sujetos activos son mujeres y los pasivos como sucedía en Schweblin- son hombres, que no se enteran de nada, que ahora están al margen, que son cuerpos y víctimas (de la seducción, de su vanidad), que mueren. Porque en el orden patriarcal, tal y como describió Bourdieu, el imaginario del amor, y la pasión, aparece bajo la dominación "femenina”:

Las fuerzas que se sospecha que actúan en la oscuridad y el secreto de las relaciones íntimas ("encima de la almohada") y que retienen a los hombres por la magia de las ataduras de la pasión puede hacer olvidar las obligaciones derivadas de su dignidad social, que determinan una inversión de la relación de dominación que, ruptura fatal del orden corriente, normal y natural, está condenada como un fallo contra natura, idóneo para reforzar la cultura androcéntrica. (133-134)

Es más, las letras de las canciones de rock -cantadas por hombres- ${ }^{34}$ redundan en la misma idea: el desamor, el abandono de la mujer, la pérdida. Ya lo enunció Fernández Porta: "La cultura musical gira alrededor de dos temas: la ruptura

34 Leemos: “También le explicaron por qué nunca elegían a mujeres para ser Estrellas: habías otras Hermanas que se ocupaban de eso. Y también de hacer otro tipo de Estrellas. Las del 
sentimental y la dinámica entre independencia y mercado” (308). Las letras de estas canciones tienen un sustrato literario y un mercado en la industria cultural, así como un grupo musical es un producto -una imagen, un estilo, un relato, un cuerpo- que consumen con voracidad las fans, en un acto casi performativo. La seducción que unos y otras ejercen en este intercambio simbólico y económico de experiencias, en esa relación misteriosa entre sujetos, se aviene a la destrucción, como advertía Ovidio. "Siempre que seducimos lo hacemos en el espectáculo y nos hacemos espectáculo” sostiene Fernández Porta (288). Los conciertos, hoy día más espectacularizados que nunca, no son otra cosa que un gran espacio público donde circula el deseo y la violencia, fuerzas que siempre actúan en el mercado neoliberal y que permean en la educación sentimental y en los procesos de subjetivación. Las Luminosas son parte sustancial de ese espectáculo que "ilumina” nuestras experiencias: mujeres que desean y agreden al mismo tiempo, consumidoras y productoras (i.e, ellas son las verdaderas hacedoras de leyendas masculinas); constructoras y destructoras, víctimas y victimarias, fanáticas y $\operatorname{asesinas}^{35}$ :

Cuando recordaba esa noche en una playa con el chico que le había metido arena en la vagina para que le raspara, para que doliera y gritara, escuchaba una canción de Fallen, cantaba I fell apart lloraba y terminaba parada sobre la cama, con los brazos extendidos, sintiendo que alguna vez iba a olvidar ese aliento a alcohol y olor a sangre. (Enríquez 56)

El asunto del cuerpo es central en esta ficción, que no solo refiere a la mujer, sino al hombre, objeto también de actos violentos. En un giro feminista, la misión de las Luminarias -mujeres sin cuerpo- es "Afectar el cuerpo del artista, enfermarlo y darle intenso dolor [que] resulta una estrategia fundamental de las Luminosas para forjar el camino de leyenda, el sufrimiento resulta constitutivo de su camino a la inmortalidad" (Pizarro Silva 51). Se aprovechan de la invisibilización -son fantasmas, hadas- que les otorga el ser mujeres, jóvenes, asimiladas a una masa (todas las fans son iguales) para acabar con la materialidad del mito -el cuerpo- que ellas mismas han construido y perpetuarlo en la tragedia, de la que se benefician materialmente ${ }^{36}$. La metáfora reproductiva del capitalismo y el no-lugar que ocupan las mujeres -sin cuerpo- es evidente, así como la crítica social y (post)feminista que destila el texto, desde una mirada

cine, por ejemplo. El territorio de las Luminosas era sólo el de los chicos y la música” (Enríquez 25).

35 La novela se inscribe a su vez en una tradición muy argentina: la genealogía literaria de mujeres asesinas de la que hablaba Josefina Ludmer en su célebre ensayo El cuerpo del delito.

36 Por supuesto, el final de estas estrellas del rock es de naturaleza romántica, para poder alcanzar el grado de leyenda: la enfermedad, el trauma, la pérdida. 
materialista que no solo cuestiona la categoría de género ${ }^{37}$ como modo de percepción del mundo, sino que revierte la materialidad de la dialéctica masculino/femenino.

Asimismo, podemos leer esta novela a partir de la psicopolítica, como síntoma del capitalismo emocional -"la emoción es dinámica, situacional y performativa" (Han 268)-, efecto de un marketing neoliberal basado en el constante consumo de sexualidad -de iconos e imágenes sexuales- que trae aparejada la erotización de cualquier producto, incluido el sujeto (hombre). Este es el caso del fenómeno de las mujeres fans -una figura tradicionalmente femenina- de estrellas del rock masculinas, que se mueven por la pura deseabilidad (Simmel) y la capitalización de emociones (Han). El artista, como sujeto neoliberal espectacularizado, se autoexplota y se autoagrede en virtud del capital y de la optimización personal (Han 19 y 51). Las fans entonces son una suerte de consumidoras autosometidas por la subjetividad/productividad del ídolo, y de su cuerpo, hasta el punto que ejercen de "panópticos" que controlan, y persiguen, la vida de los famosos. Sucede lo mismo con la religión, no en vano Benjamin concebía el capitalismo como una devoción sacramental (Han 20):

Lo sobrenatural de Este es el mar resulta así una alegoría de la condición religiosa del capitalismo, en el que las criaturas espectrales hacen de las fuerzas invisibles y metafísicas del capital y la mercancía, manipulando las relaciones humanas de acuerdo a sus intereses, produciendo y manteniendo el sentido cultual del consumo fetichista a través de su existencia mística. (Pizarro Silva 70-71)

En la misma órbita, habríamos de pensar la sobreexcitación que conlleva la imagen -el cuerpo- del ídolo como parte de la producción "farmacopornográfica", que diría Paul B. Preciado, propia de "un 'capitalismo caliente' bien distinto del sistema industrial, que generaba productos pero refrenaba las pasiones” (Fernández Porta 33). En este sentido hay una crítica a la fetichización de subjetividades y cuerpos en la sociedad global, a la (sobre)exposición que impone el mercado de la fama, muy similar a lo que sucede en la industria editorial. Los grandes grupos también explotan hasta la saciedad la imagen de los escritores -más aún de los jóvenes, de los nuevos- en actos públicos, que se han multiplicado en el siglo XXI (presentaciones, firmas, festivales, talleres, mesas redondas, entrevistas, etc.), al albur del consumo masivo de celebridades en directo. El escritor reemplaza a la obra, que ha devenido en un proyecto, casi en una "narración en directo", que debe hacerse presente in continuum en el mercado -en disputa- globalizado. Aquí

37 Huelga especificar que el género no es solo una articulación formal sino material. 
los hombres-estrella de la escritura ${ }^{38}$-si seguimos el símil, también ellos habrían conseguido el éxito por las mujeres- son reemplazados por una miríada de figuras (de éxito fugaz) entre las que encontramos, cada vez más, a mujeres escritoras. ¿Luminarias iluminadas?

\subsection{El feminicidio}

“Visibilizar, nombrar, catalogar es el primer paso para modificar”, afirma Ainhoa Vásquez Mejías (14) en un libro que analiza la ficcionalización de los feminicidios en el campo cultural chileno. Como demuestra en su estudio, este topos ha ido ganando protagonismo en la literatura latinoamericana del siglo XXI, después de que Bolaño publicara 2666 -que trata los feminicidios de Ciudad Juárez- ${ }^{39}$ en 2004. En el siglo anterior, este problema político estaba muy invisibilizado en la producción cultural mundial, considerado -incluso a día de hoy- como la "repetición constante del mito victimológico que circunscribe a la mujer en el terreno de la pasividad y al hombre en el espacio de la enfermedad" (Vásquez Mejías 18). Sin embargo, en la última década, el discurso literario ha desplazado este cliché y ha abierto nuevas ventanas a la reflexión de la violencia machista y de la responsabilidad del Estado ${ }^{40}$ que no pone freno -ideológico- a este "terrorismo institucionalizado", a las prácticas sociales que permiten los continuos abusos y agresiones que sufren las mujeres, desprotegidas dentro de la sociedad civil:

cada treinta horas ocurre un femicidio -según distintas estadísticas no oficiales, como las de la organización Mumalá (Vivanco - Mumalá, 2018)-, el aborto es la principal causa de muerte materna y continúa la lucha por la legislación del trabajo sexual. En marzo de 2015 se lleva a cabo la primera maratón de lecturas contra los femicidios, con la coordinación de María Pía López -ensayista, narradora y directora, entre 2011 y 2015, del Museo del Libro y de la Lengua, dependiente de la Biblioteca Nacional-. Tres meses después, tras el femicidio de Chiara Páez, es la primera convocatoria “Ni Una Menos”. (Angiletta 101)

38 ¿Los varones del Boom latinoamericano?

39 Aunque ya antes había representado en su literatura los crímenes de género, como en Estrella distante (1996) (Vásquez Mejías 17). Desde luego, él fue uno de los precursores del tratamiento literario de la violencia machista en el espacio literario chileno. Le siguieron más tarde Diamela Eltit que saca en 2007 Jamás el fuego nunca, Rodrigo Ramos Bañados con Alto hospicio (2008), Juan Poblete con No me ignores (2010) o Diego Zúñiga con Racimo (2015).

40 Por esta razón, se empezó a extender el término "feminicidio", que reemplaza al de femicidio en los años 90, empleado por Lagarde (2009), para visibilizar la responsabilidad -e impunidad- del Estado en los asesinatos de mujeres. De hecho, en Chile se tipificó el "femicidio" como delito punible en el Código Penal en 2010, y en 2012 se incluyó en la Argentina una modificación a su Código Penal en que se contempla el “femicidio” (Vásquez Mejías 28). 
Desde los albores del siglo XXI, la muerte de mujeres, los cuerpos desaparecidos, la violencia y el abuso son instancias literarias en el campo narrativo argentino: valgan como ejemplo, Boca de lobo (2000), de Sergio Chejfec, Chicos que vuelven (2010), de Mariana Enríquez, Beya (2013), de Gabriela Cabezón Cámara, Chicas muertas (2014), de Selva Almada o Aparecida (2015), de Marta Dillon; y en todas se concibe lo corpopolítico como corpoética de la resistencia (Audran 80). En rigor, la sexualidad es política porque lo íntimo es político y porque el cuerpo es político. Por ello en la escritura de mujeres el cuerpo como materia ha ocupado siempre un lugar cardinal, desde que el feminismo de la diferencia estableciera la analogía texto-cuerpo (véase Palaisi-Robert y Torras Francés). Es claro: el cuerpo de la mujer ha sido considerado tradicionalmente propiedad del hombre, mercancía y producto para el patriarcado, que la cosifica y somete a través de la violencia/violación: "hablamos de feminicidio justo por la inoperancia del gobierno a la hora de proteger a las mujeres en peligro y resolver los crímenes, porque su condición social precaria las hace mayormente susceptibles de transformarse en víctimas y, luego, en un número más, contenidas en hojas burocráticas” (Vásquez Mejías 164).

Esto es lo que pone de manifiesto Chicas muertas, de Selva Almada, que cuenta los feminicidios de tres jóvenes ${ }^{41}$ : Andrea Danne, María Luisa Quevedo y Sarita Mundín, acaecidos en la provincia de Entre Ríos en los ochenta. Las tres tienen en común ser víctimas de violencia machista y haberse convertido en un caso más sin resolver. La imposibilidad de darle un final al relato de sus vidas ( un libro de no ficción sin final, en el que funge de investigadora (accede a los archivos de los casos), de víctima de violencia de género, de coleccionista de versiones, de entrevistadora, y de cronista que construye una historia alternativa a la policial, y mediática, que circuló en la época. Y eso es lo importante en el texto: la construcción del relato. Digna heredera de Walsh, y del periodismo comprometido, se vale de la crónica para armar una obra de no ficción que bascula entre lo literario y el reportaje (Falbo 10). Este formato, netamente latinoamericano y vinculado desde la época colonial con lo masculino ${ }^{42}$, ha vuelto a ser muy cultivado -después del Boom- en el campo cultural argentino del siglo XXI, también por mujeres (v.g., María Moreno), donde adquiere fuertes connotaciones políticas al concebirse como un arma contra los medios hegemónicos de comunicación en manos de oligopolios

41 Las mujeres jóvenes son abordadas desde un doble cariz: la fuerza en Mariana Enríquez, y la vulnerabilidad en Selva Almada.

42 Uno de sus insignes cultivadores es José Martí. 
neoliberales. El resurgir del género tiene que ver por igual con el "retorno a lo Real" y con la pulsión de "realidad real”, tal y como sugiere Žižek, que aparece ahora -dado el mundo artificial y virtualizado en que vivimos- como una pesadilla: “a causa de su carácter traumático/excesivo, somos incapaces de integrarlo en (lo que experimentamos como) nuestra realidad" (20). La sociedad por tanto aparta/olvida los crímenes después de un periodo de morbo mediático, mientras la literatura visibiliza esta violencia machista leyendo los cuerpos -asesinados- desde otro lugar. No juzga, expone: "En once capítulos y un epílogo, Almada no sólo reconstruye las vidas de Andrea, María Luisa y Sarita, sino que también evidencia la trama de impunidad, corrupción y violencia que sostiene la sociedad patriarcal” (Elizondo Oviedo 3).

Como Diamela Eltit en Jamás el fuego nunca, Selva Almada establece una “estrecha relación" - no evidente- "entre patriarcado, ideología política y feminicidio” (Vásquez Mejías 153). De esta manera, el vínculo entre sexualidad y violencia reproduce "oposiciones fundadoras del orden simbólico" tales como activo/pasivo y dominante/dominada, que propician la violencia simbólica y física sobre la mujer:

\footnotetext{
El mundo social construye el cuerpo como realidad sexuada y como depositario de principios de visión y de división sexuantes. El programa social de percepción incorporado se aplica a todas las cosas del mundo, y en primer lugar al cuerpo en sí, en su realidad biológica: es el que construye la diferencia entre los sexos biológicos de acuerdo con los principios de una visión mítica del mundo arraigada en la relación arbitraria de dominación de los hombres sobre las mujeres. (Bourdieu 22-24)
}

Si el cuerpo es la única certeza -material- en el capitalismo neoliberal, tal y como ilustra la novísima narrativa argentina (Drucaroff, Los prisioneros 469), la agresión ejercida al cuerpo de la mujer es una forma de negarle su materialidad; una subjetividad propia. Chicas muertas va más allá y presenta cuerpos muertos de mujeres adolescentes en un contexto rural, provinciano, que se yergue como un no-centro, un espacio marginal, propicio para el secreto, el ocultamiento, el asesinato y la violación. La idea del asesino ligado a la barbarie vuelve, pero también se asocia al Estado, a los policías e investigadores que no han sabido detener a los culpables. E incluso la barbarie salpica a la ciudadanía, a la opinión pública más preocupada por el relato, por el morbo, que por los cuerpos.

En definitiva, Almada huye de lo simbólico, de la alta cultura y de la retórica, para trabajar con lo real mediante significantes de la educación social del patriarcado, la cultura de masas y la subjetivación de las mujeres, entremezclando múltiples puntos de vista: medios de comunicación, testigos, amigos, familiares, informes policiales, tarotistas, y el de ella misma: 
A mis doce años esa noticia me había impactado muchísimo. ¿Cómo podía ser que el marido la violara? Los violadores siempre eran hombres desconocidos que agarraban a una mujer y se la llevaban a algún descampado o que entraban a su casa forzando una puerta. Desde chicas nos enseñaban que no debíamos hablar con extraños y que debíamos cuidarnos del Sátiro. El Sátiro era una entidad tan mágica como, en los primeros años de la infancia, la Solapa o el Viejo de la Bolsa. Era el que podía violarte si andabas sola a deshora o si te aventurabas por sitios desolados. El que podía aparecer de golpe y arrastrarte hasta alguna obra en construcción. Nunca nos dijeron que podía violarte tu marido, tu papá, tu hermano, tu primo, tu vecino, tu abuelo, tu maestro. Un varón en el que depositaras toda tu confianza. (Almada 54-55)

Estas revelaciones íntimas son abordadas con crudeza y nitidez en una composición narrativa que lleva al lector/a a la emancipación y al empoderamiento, mediante la visibilidad y la exposición de parcialidades. Así, la fragmentación y la proliferación de versiones pueden ser interpretadas como una ruptura de la unidad patriarcal, o como "resistencia a la significación”. Si "la cultura nos hace construir totalidades homogéneas, imaginarios” (Padilla 19) machistas, producir un texto sobre la base de imágenes parciales, relatos a medias y diálogos interrumpidos, es una manera -feminista- de desestabilizar el discurso hegemónico: literario y social.

\section{Conclusiones}

Al comienzo de este artículo señalaba que lo que verdaderamente nuevo de la literatura argentina del siglo XXI es el destacado lugar que ocupan las escrituras de mujeres, caracterizadas por la radicalidad de sus propuestas y por el tratamiento postfeminista de temas como la maternidad, el amor romántico o la violencia. El género funciona en sus poéticas como un molde sobre el que se construye cada una de las obras, un filtro entre el texto y lo político. En el epicentro, estaría la cuestión de la materialidad de los cuerpos de las mujeres, que es problematizada desde diversos feminismos ${ }^{43}$ y materias: el cuerpo de una madre, el de un niño, el de un hombre, y el de las víctimas de violencia machista:

La violencia contra la mujer no es sólo física parecen decir estos textos cuando refractan el escenario de una sociedad que a través de la institución familiar reprime deseos, naturaliza roles y abandona a subjetividades adscriptas al género femenino atravesadas o interpeladas por la experiencia de la maternidad, que intentan resistir los mandatos y ensayar formas de empoderamiento en los bordes de la animalidad, la locura o la enfermedad. (Maradei 27)

43 Opuesto al cuerpo femenino por antonomasia, que en la literatura argentina habría de encarnarlo Eva Perón (véase Coria). 
Pero no se trata de una generación de mujeres, sino más bien de un núcleo de escritoras que entienden el feminismo como un proceso de construcción de la identidad; como la narración material de la complejidad de los cuerpos; como un relato plural (global); como un trabajo con lo factual y lo documental (que pone en cuestión las formas hegemónicas de dar cuenta de lo real); como la práctica de ciertos géneros menores o "masculinos” (lo fantástico en Schweblin y Enríquez, y la crónica en Almada); como el uso de un lenguaje crudo, directo y procaz, desliteraturizado; como un modo de visibilización y resistencia frente a la univocidad del discurso patriarcal.

En las tres novelas argentinas que componen nuestro archivo no encontramos nuevas técnicas o temas literarios, sino nuevas actitudes o posturas feministas, que operan como un dispositivo a partir del cual se discuten los procesos de subjetivación de (todas) las mujeres -ambiguos, performáticos y monstruosos- y se resignifica -desde lo sombrío, lo siniestro- la construcción masculina de lo femenino. Esto evidencia cómo la literatura mundial se apropia de estas literaturas latinoamericanas que devienen instancias de lucha contra la experiencia patriarcal y la (re)producción de subjetividades feministas, convirtiéndose en una mercancía feminista -del feminismo hegemónico- en sí. No hay que soslayar que nuestro corpus se ha editado en un mismo sello -Literatura Random House, que pertenece a un gran conglomerado-, diseñado a tenor de una política acumulativa de capital simbólico y económico, que ha ido integrando en los últimos años a más mujeres en su catálogo. Mujeres profesionales que han asistido a talleres de escritura, mujeres que publican y viven de sus novelas, mujeres representadas por reputados agentes literarios, mujeres que circulan en el ámbito transnacional del hispanismo, mujeres que se traducen al inglés, mujeres que narran a otras mujeres ${ }^{44}$. Mujeres que comparten no solo una temporalidad o un sensorium -el feminismo globalizado del siglo XXI- sino un espacio internacional en que priman la materialidad de una lengua castellana neutra, la subjetividades globales y las poéticas feministas no contrahegemónicas -decoloniales, latinoamericanas- sino mundiales.

Al cabo, estas obras de Schweblin, Enríquez y Almada no solo representan experiencias de mujeres -maternidad, amor y violencia- sino que son consecuencia de una postura feminista adoptada por una miríada de escritoras del mundo. Escritoras que actúan en ese mundo iluminando las condiciones falologocéntricas en que se han (re)producido los sujetos femeninos, que circulan en el siglo XXI como feministas. Escritoras que han decidido situarse ahora en el lugar más sombrío, debajo de la lámpara.

44 Y no solo a sí mismas, es decir, relatos que se ubican afuera del intimismo propio del discurso femenino y de la literatura del siglo XXI, muy autorreferencial y anclada en el yo. 


\section{Bibliografía}

Almada, Selva. Chicas muertas. Literatura Random House, 2015.

Angilletta, Florencia. "Ficciones argentinas desde el género: un archivo vivo". Tropelías.

Revistas de Teoría de la Literatura y Literatura Comparada, 3, 2018, pp. 95-103.

Audran, Marie. "Resistencias corpopolíticas en Argentina: monstruos femeninos levantándose contra la desaparición". Revell, 17, 2017, pp. 76-96.

Blanco, Fernando A. et al. (eds.). Políticas del amor: derechos sexuales y escrituras disidentes en el Cono Sur. Cuarto Propio, 2018.

Bourdieu, Pierre. La dominación masculina. Anagrama, 2000.

Bourriaud, Nicolas. Radicante. Adriana Hidalgo, 2009.

Cheah, Pheng. What is a World? Duke University Press, 2016.

De Leone, Lucía. “Campos que matan. Espacios, tiempos y narración en Distancia de rescate de Samanta Schweblin”. 452 ${ }^{\circ} F, 16,2017$, pp. 62-76.

Crespi, Maximiliano. Los infames. La literatura de derecha explicada a los niños. Momofuku, 2015.

Domínguez, Nora. De donde vienen los niños. Maternidad y escritura en la cultura argentina. Beatriz Viterbo, 2007.

Drucaroff, Elsa. "La cicatriz de lo que no se pronuncia (Apuntes sobre Distancia de rescate, de Samanta Schweblin)”. XXX Jornadas de Investigación del Instituto de Literatura Hispanoamericana Facultad de Filosofía y Letras. Universidad de Buenos Aires, 2018.

---. Los prisioneros de la torre. Política, relatos y jóvenes en la postdictadura. Emecé, 2011.

Elizondo Oviedo, María Verónica. "Femicidio y exhumación del archivo en Chicas muertas de Selva Almada”. IV Congreso Internacional de Cuestiones Críticas del CELARG. Universidad Nacional de Rosario, 2015. http://www.celarg.org/int/arch_publi/elizondooviedocc2015. pdf, consultado 20 de julio 2018.

Enríquez, Mariana. Éste es el mar. Literatura Random House, 2018.

Falbo, Graciela. "Periodismo y escritura: las discípulas de Walsh”. Trampas de la comunicación y la cultura, 80, 2017, pp. 1-13. http://sedici.unlp.edu.ar/bitstream/han dle/10915/64584/Documento_completo.pdf-PDFA.pdf?sequence=1\&isAllowed=y, consultado 13 de julio 2018.

Falconí Trávez, Diego et al. (eds.). Resentir lo queer en América Latina: diálogos desde/con el Sur. Egales, 2016.

Femenías, María Luisa y Paula Soza Rossi. Saberes situados, teorías trashumantes. Editorial CINIG-IdIHCS, 2011.

Fernández Porta, Eloy. €RO\$. La superproducción de los afectos. Anagrama, 2010.

Gallego Cuiñas, Ana. "Poéticas del mercado global en América Latina". Eds. O. Estrada y E.Valero. Literatura y globalización. Latinoamérica en el nuevo milenio. Anthropos, 2019. En prensa.

--.. "Las narrativas del siglo XXI en el Cono Sur: estéticas alternativas, mediadores independientes”. Ínsula, 859-860, 2018, pp. 9-13.

--.. “Comienzos de la novísima novela argentina (2001-2011)”. Hispamérica, 130, 2015, pp. 3-14.

González Dinamarca, Rodrigo Ignacio. “Los niños monstruosos en El orfanato de Juan Antonio Bayona y Distancia de rescate de Samanta Schweblin”. Brumal. Revista de investigación sobre lo fantástico, III, 2, 2015, pp. 89-106. 
Han, Byung-Chul. Psicopolítica. Neoliberalismo y nuevas técnicas de poder. Herder, 2015. Lagarde, Marcela. "Claves feministas en torno al feminicidio". Nuevas líneas de investigación en género y desarrollo. Coords. Estefanía Molina y Nava San Miguel. Universidad Autónoma de Madrid, 2009, pp. 211-233.

Locane, Jorge J. De la literatura latinoamericana a la literatura (latinoamericana) mundial. Condiciones materiales, procesos y actores. De Gruyter, 2019.

Ludmer, Josefina. Aquí América Latina. Una especulación. Eterna Cadencia. 2010.

--.. Clases 1985. Algunos problemas de teoría literaria. Paidós, 2015.

Maradei, Gudalupe (2016): “Cuerpos que insisten: familia, matrimonio y maternidad en la literatura argentina de la última década”. Chasqui, 45, 2016, pp. 1-31. https://www.aca demia.edu/25412680/Cuerpos_que_insisten_familia_matrimonio_y_maternidad_en_la_ literatura_argentina_de_la_\%C3\%BAltima_d\%C3\%A9cada, consultado 5 de julio 2018.

Medeiros-Lichem, Maria Teresa. Reading the Feminine Voice in Latin American Women's Fiction: From Teresa de la Farra to Elena Poniatowska and Luisa Valenzuela. Peter Lang, 2002.

Marazzi, Christian. Capital and Language. From the New Economy to the War Economy. Semiotext(e), 2008.

Müller, Gesine y Dunia Gras (eds.). América Latina y la literatura mundial. Mercado editorial, redes globales y la invención de un continente. Iberoamericana/Vervuert,2015.

Müller, Gesine, Jorge J. Locane y Benjamin Loy (eds.). Re-mapping World Literature: Writing, Book Markets and Epistemologies between Latin American and the Global South. De Gruyter, 2018.

Orechia Havas, María Teresa. "Cruzando límites: cuestiones críticas y formas actuales de la narrativa escrita por mujeres”. Pasavento, 2, 2014, pp. 407-431. https://ebuah.uah.es/ dspace/bitstream/handle/10017/23903/cruzando_orecchia_PASAVENTO_2014_V2_N2. pdf? sequence=1\&isAllowed=y, consultado 20 de diciembre 2018.

Padilla, José Ignacio. El terreno en disputa es el lenguaje. Ensayos sobre poesía latinoamericana. Iberoamericana/Vervuert, 2014.

Palaisi-Robert, Marie-Agnès y Meri Torras Francés (eds.). El cuerpo en juego: cartografía conceptual y representaciones en las producciones culturales latinoamericanas. Mare \& Martin, 2014.

Parks, Tim. Where l'm Reading. The Changing World of Books. Harvill Secker, 2014 [versión ebook].

Pizarro Silva, Felipe. El espectáculo que nos afecta. La vida en las ventanas (2002) de Andrés Neuman y Éste es el mar (2017) de Mariana Enríquez, Universidad de Chile, 2017, pp. 1-94. http://repositorio.uchile.cl/bitstream/handle/2250/146995/El-espectaculoque-nos-afecta.pdf?sequence=1\&isAllowed=y, consultado 10 de julio 2018.

Poblete, Juan. “Globalización, mediación cultural y literatura nacional”. América Latina en la literatura mundial. Ed. Ignacio M. Sánchez Prado. Instituto Internacional de Literatura Iberoamericana, 2006, pp. 271-306.

Riveiro, María Belén. "Los talleres literarios: el caso de los escritores de narrativa en la Ciudad de Buenos Aires". XI Jornadas de Sociología. Facultad de Ciencias Sociales. Universidad de Buenos Aires, 2015, pp. 1-13. http://www.aacademica.org/000-061/249, consultado 9 de julio 2018. 
Rowinsky, Mercedes. "Super-mujer: estrategias femeninas ante la maternidad en el discurso literario del siglo XX". Actas del XIV Congreso de la Asociación Internacional de Hispanistas, 2014, pp. 425-432. https://cvc.cervantes.es/literatura/aih/pdf/14/aih_14_ 1_049.pdf, consultado 19 de julio 2018.

Sánchez Prado, Ignacio M. Strategic Occidentalism. On Mexican Fiction, the Neoliberal Book Market and the Question of World Literature. Northwestern University Press, 2018.

Sapiro, Gisèle (ed.). Les contradictions de la globalisation éditoriale. Nouveau Monde, 2009. Sarlo, Beatriz. Ficciones argentinas. 33 ensayos. Mardulce, 2012.

Schlickers, Sabine. "La mujer trastornada en la literatura del siglo XXI: La fiesta del chivo (2000) de Mario Vargas Llosa, Letargo (2000/2014) de Perla Suez, Distancia de rescate (2014) de Samanta Schweblin y ‘El último día de las vacaciones’ (2008) de Inés Garland”. Revista Estudios, 31, 2015, pp. 1-17.

Schweblin, Samanta. Distancia de rescate. Literatura Random House, 2015.

Soria, Claudia. Los cuerpos de Eva. Anatomía del deseo femenino. Beatriz Viterbo, 2005.

Terranova, Juan. Los gauchos irónicos. milena caserola, 2013.

Vásquez Mejías, Ainhoa Montserrat. Feminicidio en Chile. Una realidad ficcionada. Cuarto Propio, 2015.

Žižek, Slavoj. Bienvenidos al desierto de lo real. Akal, 2008. 